\title{
RNA-Mediated Gene Silencing of Superoxide Dismutase (bcsod1) in Botrytis cinerea
}

\author{
R. M. Patel, J. A. L. van Kan, A. M. Bailey, and G. D. Foster
}

First, third, and fourth authors: School of Biological Sciences, University of Bristol, BS8 1UG, UK; and second author: Laboratory of Phytopathology, Wageningen University Plant Sciences, The Netherlands. Accepted for publication 21 August 2008.

\begin{abstract}
Patel, R. M., van Kan, J. A. L., Bailey, A. M., and Foster, G. D. 2008. RNA-mediated gene silencing of superoxide dismutase (bcsodl) in Botrytis cinerea. Phytopathology 98:1334-1339.

Gene silencing is a powerful tool utilized for identification of gene function and analysis in plants, animals, and fungi. Here, we report the silencing of superoxide dismutase (bcsodl) in Botrytis cinerea through

Plate-based assays with and without paraquat were performed to screen initial silencing efficiency, and a subset of transformants was used for in planta studies of virulence. Transformants exhibiting strongly decreased transcripts levels were recovered with both constructs but none of those exhibited a reduction in virulence in planta. Our investigations may help optimize a high-throughput gene silencing system useful for identifying potential gene targets for future fungal control.
\end{abstract} sense and antisense-mediated silencing mechanisms. Because superoxide dismutase (SOD) is a virulence factor, transformants were tested for phenotypic silencing in vitro and reduction in pathogenicity in planta.
Additional keywords: posttranscriptional gene silencing, RNAi.
Sequence-specific RNA silencing is an invaluable tool that allows for the functional analysis and screening of genes in order to identify potential pathogenicity factors. Silencing was first observed in Petunia and termed "cosuppression" (24). It is also referred to as RNA interference (RNAi) in animals, posttranscriptional gene silencing (PTGS) in plants, and quelling in fungi $(13,18,35)$. Collectively, these processes are referred to as PTGS. Because this phenomenon has been observed in a wide range of organisms, its mechanism and biological purpose is thought to be highly conserved across kingdoms. Fundamentally, gene silencing is mediated by RNA molecules and is intricately linked with transcription of the target gene. It results from a sequence-specific degradation of messenger RNAs (mRNAs) induced by the formation of aberrant double-stranded RNA (dsRNA). The dsRNA is processed into 21- to 25-nucleotide fragments called short interfering RNAs (siRNA) by a Dicer enzyme $(3,11,21)$. Individual siRNAs are then integrated into a RNA-induced silencing complex (RISC), an endonuclease that targets mRNA complementary to the incorporated siRNA sequence $(12,38)$.

Although gene silencing is normally involved in genome defense, researchers are able to manipulate gene expression of endogenous- and trans-genes through the generation of dsRNA molecules complementary to the target gene, making it an invaluable tool for gene discovery and function (23). It is believed that the benefits observed from gene silencing may be demonstrated for the plant pathogen Botrytis cinerea, a necrotrophic fungus capable of infecting over 200 plant species worldwide (37). Primarily, the fungus infects dicotyledonous crops such as fruit berries, vegetables, cut flowers, potted plants, and grapevine. Unlike many plant pathogens, $B$. cinerea is prominent all year round and causes infection under a broad range of environmental

Corresponding author: G. D. Foster; E-mail address: Gary.Foster@Bristol.ac.uk

* The $\boldsymbol{e}$-Xtra logo stands for "electronic extra" and indicates that Figure 5 appears in color online.

doi:10.1094/PHYTO-98-12-1334

(C) 2008 The American Phytopathological Society conditions (15). Because $B$. cinerea is resilient against natural plant defensive measures and various fungicides $(6,17,19)$, new target genes affecting pathogenicity must be uncovered before additional forms of control can be developed.

To develop a gene silencing system in $B$. cinerea, we selected the endogenous gene superoxide dismutase (bcsodl), an $\mathrm{H}_{2} \mathrm{O}_{2}-$ generating enzyme (25). Superoxide dismutases (SODs) belong to a family of enzymes that neutralize the effect of active oxygen species (AOS). Specifically, SOD catalyzes the conversion of $\mathrm{O}_{2}^{-}$ into $\mathrm{H}_{2} \mathrm{O}_{2}$ (8). The expression of bcsodl, a single-copy gene, has been characterized in vitro and in planta, and knockout mutants in this gene show reduction in virulence (25). As a result, silencing efficiencies can be assessed or compared in vitro and in vivo to better understand SOD production levels. Because this is the first report of gene silencing in $B$. cinerea, RNAi technology may be used in screening unknown genes from the recently sequenced $B$. cinerea genome.

\section{MATERIALS AND METHODS}

Fungal strains and growth conditions. Experimental analyses and transformation were performed on $B$. cinerea haploid strain B05.10 (4). B. cinerea conidia were stored as glycerol stocks at $-80^{\circ} \mathrm{C}$. Three SOD deletion mutants $-\Delta$ bcsod-1, -2 , and -3 (kindly provided by P. Tudzynski, University of Munster, Germany) - were used to establish the maximum reduction in growth in vitro and in planta (25). The fungus was grown on malt agar containing 5\% malt extract and $1.8 \%$ agar and incubated at $20^{\circ} \mathrm{C}$ under near-UV light to induce sporulation. Conidia were harvested 7 to 14 days postinoculation in $10 \mathrm{ml}$ of water containing $0.05 \%$ (vol/vol) Tween 80 and collected by centrifugation at 3,000 $\times g$ for $5 \mathrm{~min}$. For DNA extraction, $5 \%(\mathrm{wt} / \mathrm{vol})$ malt extract broth was inoculated with $5 \times 10^{8}$ spores and incubated at $20^{\circ} \mathrm{C}$ and $180 \mathrm{rpm}$ for $24 \mathrm{~h}$. Fungal mass was harvested by centrifugation and lyophilized.

Transformation of $\boldsymbol{B}$. cinerea. Transformants were produced using methodology described by Hamada (10) with modifications described by van Kan et al. (33). 
Standard nucleic acid techniques. Fungal genomic DNA was isolated as described (30). Polymerase chain reaction (PCR) analysis was performed as described by Saiki et al. (27) using Reddy Mix (Bioline) and amplification products were separated by gel electrophoresis. Primers used during PCR analysis are listed in Table 1. Purified products (Wizard Gel Extraction Kit; Promega Corp., UK) were cloned using the pCR 2.1 TOPO Cloning Kit (Invitrogen, UK). Ligation strategies were designed using Clone Manager Suite (Science \& Educational Software). Sequence analysis and alignment were aided by BLAST analysis at the National Center for Biotechnology Information (1). Northern analysis of total RNA was completed according to Sambrook et al. (28) with slight modifications. Total RNA was electrophoresed through a denaturing gel (1.2\% agarose, $2.2 \mathrm{M}$ formaldehyde, $1 \times$ MOPS gel). Autoradiographs were quantified by densitometry analysis (Gene Tools; Syngene, UK) within a linear signal range and normalized to ribosomal 28S RNA levels.

SOD plate-based assay. SOD activity was tested using malt extract plates supplemented with $15 \mathrm{mM}$ paraquat (1,1'-dimethyl4,4'-bipyridinium dichloride hydrate; ABCR GmbH \& Co., Germany). Plates were incubated at $20^{\circ} \mathrm{C}$ for 3 days before radial measurements were taken. Silencing frequencies (percent) were calculated by comparing the colony diameters in the presence and absence of paraquat for both the transformant and the wild-type recipient strain.

Pathogenicity assays. In planta studies were conducted on 14-day-old dwarf French bean plants (cv. Tendergreen). Conidia of the sporulating wild type and transformants of $B$. cinerea were harvested and resuspended in water at a working concentration of $1 \times 10^{6}$ conidia $\mathrm{ml}^{-1}$. Punctured plant leaves were then inoculated with a single droplet containing $5 \times 10^{3}$ conidia from the wild type and a transformant of $B$. cinerea. Leaves were incubated over a period of 5 days with diurnal cycles of $16 \mathrm{~h}$ of light and $8 \mathrm{~h}$ of darkness and $100 \%$ humidity before being photographed. Areas of infection were then determined with ImageJ software.

Construction of sense and antisense silencing vectors. The principal aim of this study was to induce gene silencing in $B$. cinerea so that it may be optimized for gene function investigations. To do so, we utilized an effective vector system, pLOB1 (R. M. Patel, unpublished data). The pLOB1 vector system consists of the pLOB1-MCS expression vector (with a 120-bp multiple cloning site) and pLOB1-HYG hygromycin resistance cassette (Fig. 1A). Both vectors are controlled by the Aspergillus nidulans oliC promoter and what is reported to be the $B$. cinerea tubA terminator, each isolated from the $\mathrm{pLOB} 1$ hygromycin resistance cassette (33). Sense and antisense bcsodl silencing constructs were amplified from $B$. cinerea cDNA (GenBank accession no. AJ555872), with primers SSOD F and SSOD R, and ASOD F and ASOD R (Table 1), respectively. Amplified fragments (581 bp in length) represent bases 12 to 465 of the coding region and $128 \mathrm{bp}$ of the 3 ' untranslated region. The sense construct was designed with a start-stop (ATG/GGG/TAA) sequence to prevent transcriptional readthrough and gene overexpression. Both PCR fragments were flanked by $N c o I$ and BamHI restriction sites and ligated into the NcoI- and BamHI-digested pLOB1-MCS vector, between the promoter and terminator regions. The resulting silencing vectors, pLOB1-SSOD and pLOB1-ASOD (Fig. 1B and $C)$, were subsequently transformed into $B$. cinerea to test for silencing capabilities in B. cinerea.

\section{RESULTS}

Selection and screening of SOD-silenced transformants. Silencing of the bcsodl gene was achieved by co-transforming either the sense or antisense silencing constructs along with pLOB1, encoding the hygromycin resistance gene. After several rounds of subculturing, transformants were screened on paraquat plate-based assays to determine silencing efficiencies by phenotypic screening (Fig. 2). Colony radii were measured 3 days postinoculation. The bcsodl-knockout mutants ( $\Delta$ bcsodl-1, $\Delta b c s o d 1-$ 2 , and $\Delta b c s o d 1-3$ ) exhibited minimal growth (radial growth of $3 \mathrm{~mm}$ ) on paraquat but demonstrated wild-type growth (radial growth of $21 \mathrm{~mm}$ ) rates in the absence of paraquat, whereas the wild type demonstrated a $29 \%$ reduction of growth with paraquat. A ratio of $36 \%$ of all recovered transformants (27\% of sense and $47 \%$ of antisense) demonstrated intermediate (33 to $65 \%$ ) or high levels (66 to $85 \%$ ) of growth reduction when compared with the wild type (Table 2). In all, 11 transformants (6 sense: S44, S150, S154, S156, S160, and S165; and 5 antisense: A76, A100, A101, A162, and A164) showing varying degrees of growth reduction, indicative of silencing, were chosen for further experimentation. Select transformants exhibited a significant $(F$ was significant at $P=0.0002)$ reduction in radial growth compared with the wild type on plates supplemented with paraquat. Overall, the bcsodl knockout mutant showed an $85 \%$ reduction in colony diameter on plates supplemented with paraquat (compared with growth without treatment), whereas the wild type demonstrated a $29 \%$ reduction in growth. Selected transformants exhibited a range of growth reduction between 32 and $71 \%$ (Fig. 3).

Analysis of construct integration. PCR was performed on chosen transformants (S44, S150, S154, S156, S160, S165, A76, A100, A101, A162, and A164) and the wild-type strain to examine integration of the silencing construct into the $B$. cinerea genome. Primers SOD DNA F and SOD DNA R (Table 1) amplified the bcsodl gene (with introns), confirming the presence of an intact endogenous bcsodl gene in all transformants and wild-type samples. The presence of an intact silencing and hygromycin construct in all tested transformants was confirmed using primers OLIC2 and TUB2, which anneal to the oliC promoter and terminator region.

Determination of mRNA expression levels. The bcsodl transcript levels were determined by northern analysis using a DNA probe amplified from $b c s o d l$ cDNA with primers SOD RNA F and SOD RNA R (Table 1). Densitometry analysis was used in normalizing for differences in loading based on rRNA levels (Fig. 4A and B). High levels of silencing are defined as SOD transcript levels 1 to $30 \%$ compared with the wild type, while medium and low levels of silencing are defined as SOD transcript levels of 31 to $60 \%$ and 61 to $90 \%$, respectively. According to the autoradiograph result and subsequent densitometric comparison with

TABLE 1. Primer list and sequences utilized for vector construction, screening, and northern analysis of Botrytis cinerea isolates

\begin{tabular}{|c|c|}
\hline Primer name & Primer sequence $5^{\prime}-3^{\prime}$ \\
\hline ASOD F & GGGGATCCGCAGTTGCTACCGTCCGCGGTG \\
\hline ASOD R & GGCCATGGAGTAGAACGATTGCTTTTCTGTTAAAAC \\
\hline OLIC2 & ATTAAGCGGGAGACGTATTT \\
\hline SOD DNA F & ATTCTTCTCATATGTTGCTTTCCTCTT \\
\hline SOD DNA R & TCATGTCATTTTGTATGCTACATTTA \\
\hline SOD RNA F & ATGGTTAAAGCAGTTGCTACCGTCC \\
\hline SOD RNA R & TTATGCAGCAATACCGATAACACC \\
\hline SSOD F & GGCCATGGGGTAAGCAGTTGCTACCGTCCGCGGTG \\
\hline SSOD R & GGGGATCCAGTAGAACGATTGCTTTTCTGTTAAAAC \\
\hline TUB2 & GGGACTTGAGACCGATGAAAC \\
\hline
\end{tabular}


the wild type, transformants S154, S156, S160, and A162 exhibited high levels of silencing, while samples S150 and A164 demonstrated medium levels of silencing. Samples S165 and A101 displayed low levels of silencing, while S44, A76, and
A100 showed levels equal to or greater than the wild type. Of all tested transformants, S160 demonstrated the greatest reduction in bcsodl transcript levels (79.2\%). As expected, the knockout mutant $(\Delta b c s o d 1-1)$ did not generate detectable levels of bcsodl.

A

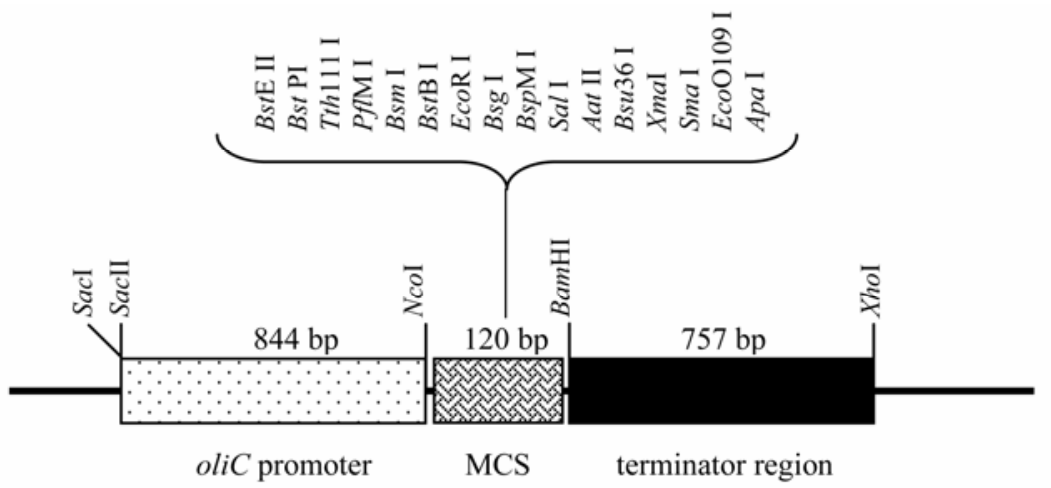

$4577 \mathrm{bp}$

B

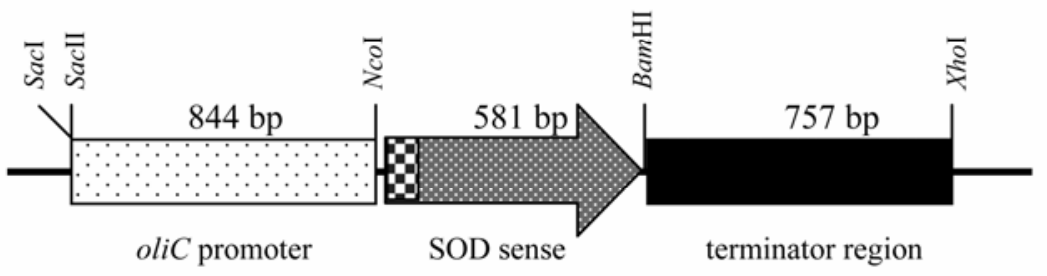

$5083 \mathrm{bp}$

C

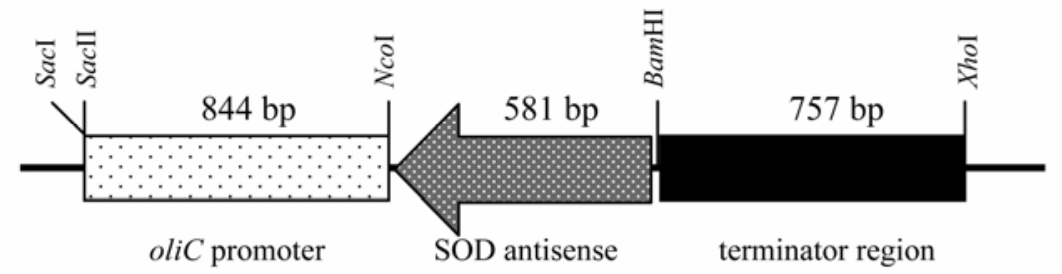

5083 bp

Fig. 1. pLOB1-multiple cloning site (MCS) and silencing plasmids. Regulatory sequences are the Aspergillus nidulans oliC promoter and what is reported to be the Botrytis cinerea tubA terminator (27). A, pLOB1-MCS contains a 120-bp MCS. B, pLOB1-SSOD contains the sense superoxide dismutase (SOD) silencing construct with start-stop sequence (;ATG/GGG/TAA, checkered box), while C, pLOB1-ASOD contains SOD in the antisense orientation. Amplified fragments (581 bp in length) represent bases 12 to 465 of the coding region and $128 \mathrm{bp}$ of the $3^{\prime}$ untranslated region. Transcript and regulatory sequence sizes are found above each segment, while construct sizes are denoted at the end of each plasmid.

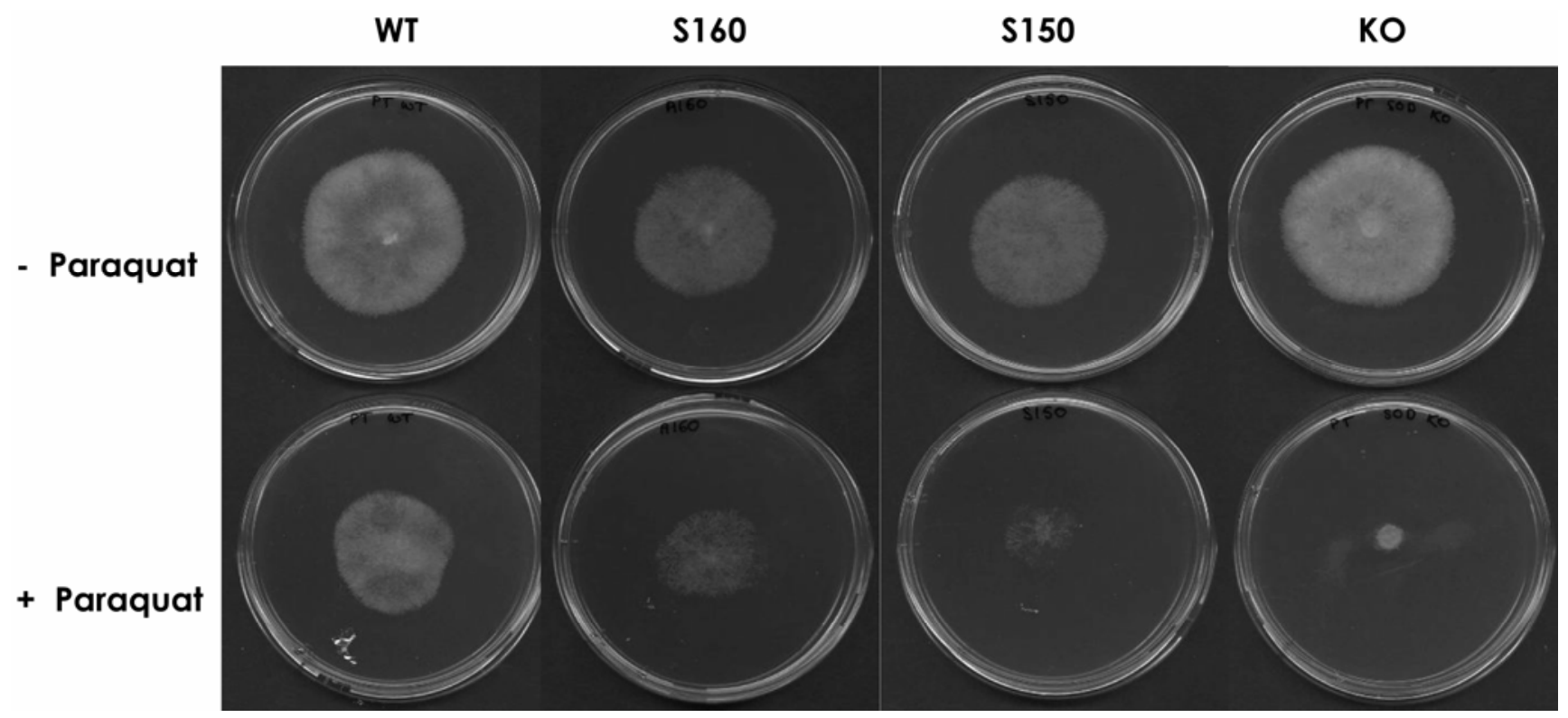

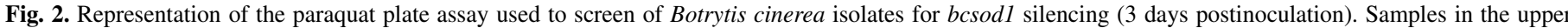

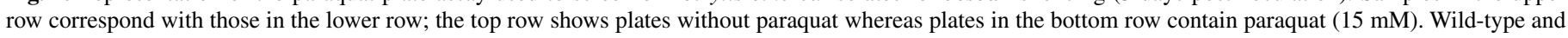
knockout samples were grown according to Rolke et al. (25). Transformants S160 and S150 demonstrate the silenced phenotype. 
Pathogenicity of transformants. Previous studies reported that bcsodl mutants $\Delta b \operatorname{csod} 1-1, \Delta b \operatorname{csod} 1-2$, and $\Delta b \operatorname{csod} 1-3$ displayed a reduction in virulence (25). Therefore, silenced transformants can be similarly tested for a reduction in pathogenicity, which may determine the residual SOD concentration required for normal (wild-type) virulence. Transformants selected demonstrated high (S154, S156, S160, and A162) or intermediate (S150 and A164) levels of bcsodl downregulation and, therefore, were expected to also exhibit a reduction in virulence. Primary leaves of dwarf French bean plants were inoculated with spores of the wild type, knockout, and six silenced transformants (Fig. 5). The area of the lesion was recorded after 72 and $96 \mathrm{~h}$ postinoculation (hpi). In total, each sample (wild type, knockout, and transformants) was tested four times (four replicates in one experiment). Initial observations found that lesion development was similar in all strains, including the wild type and knockout, regardless of activity observed during plate-based analysis; all samples exhibited an average radius of growth of 3 to $4 \mathrm{~mm}$ at $72 \mathrm{hpi}, 8$ to $9 \mathrm{~mm}$ at $96 \mathrm{hpi}$, and complete maceration after 5 days. The equivalent growth rates between the wild-type and knockout samples were unexpected; therefore, an additional 15 French bean leaves were inoculated with the wild-type and knockout strains to confirm effects of pathogenicity in planta. Overall, infection rates (Fig. 5) of the knockout mutant were rather variable, as previously described by Rolke et al. (25) However, statistical analysis indicates that the area of necrosis for the wild type and knockout were equivalent ( $t$ test, $F$ value not significant at $P=0.914$ ).

\section{DISCUSSION}

Gene silencing has become a powerful tool for reverse genetics; by refining methodologies, silencing can serve to investigate and determine gene function quickly and efficiently. In contrast to gene knockout by homologous recombination, gene silencing is a dominant trait, which makes it feasible to perform gene function analysis in organisms with a diploid genome or in haploid fungi a multinucleate thallus, such as $B$. cinerea. In plant-pathogenic fungi, successful gene silencing was first reported in Magnaporthe grisea (16) and Venturia inaequalis (7). The B. cinerea SOD gene bcsodl was targeted to determine the potential and efficiency of silencing in $B$. cinerea. Paraquat plate-based assays served to determine initial SOD silencing frequencies. As expected, the wild type grew on plates with paraquat more slowly than on plates without paraquat. The $\Delta b c \operatorname{sodl}$ gene knockout mutants exhibited minimal growth with paraquat, whereas transformants containing silencing constructs exhibited varying degrees of growth reduction with paraquat supplementation (ranging from similar to the wild type to $71 \%$ reduction in colony radius), signifying a range of SOD silencing levels. Knockout mutants and silenced transformants exhibited growth similar to the wild type without paraquat supplementation. Overall, plate-based analysis indicated that silencing was feasible using sense and antisense silencing constructs. Antisense-based constructs yielded a higher percentage of transformants with silenced phenotypes compared with sense-based constructs. The increase in observed antisense silencing frequencies may be attributed to the fact that complementary gene sequences promote the formation of RNA-RNA complexes between antisense and sense endogenous RNA mo- lecules $(2,36)$. Previous studies have found that, although sense and antisense silencing constructs are both capable of inducing gene silencing, they are only moderately efficient. For instance, it has been observed that only 5 to $20 \%$ of transformants showed a decrease in mRNA production in Arabidopsis thaliana $(29,32)$. Because bcsodl transformants demonstrated a significantly higher percentage of transformants displaying silencing during platebased assays, comparisons cannot be made with mRNA silencing frequencies observed in A. thaliana. However, when Neurospora crassa was transformed with a plasmid containing the entire al-1 gene, a simple plate-based visual inspection revealed that $\approx 30 \%$ of recovered transformants exhibited silencing phenotypes $(9,26)$. These frequencies are similar to those observed during sensemediated silencing in Botrytis spp. $(\approx 27 \%)$. However, it should be noted that all recovered transformants were subjected to in vitro plate-based analysis without the confirmation of silencing cassette integration. As a result, SOD silencing frequencies may be greater than those observed in $N$. crassa. Overall, plate-based and northern analyses confirm bcsodl downregulation, the first report of gene silencing in B. cinerea.
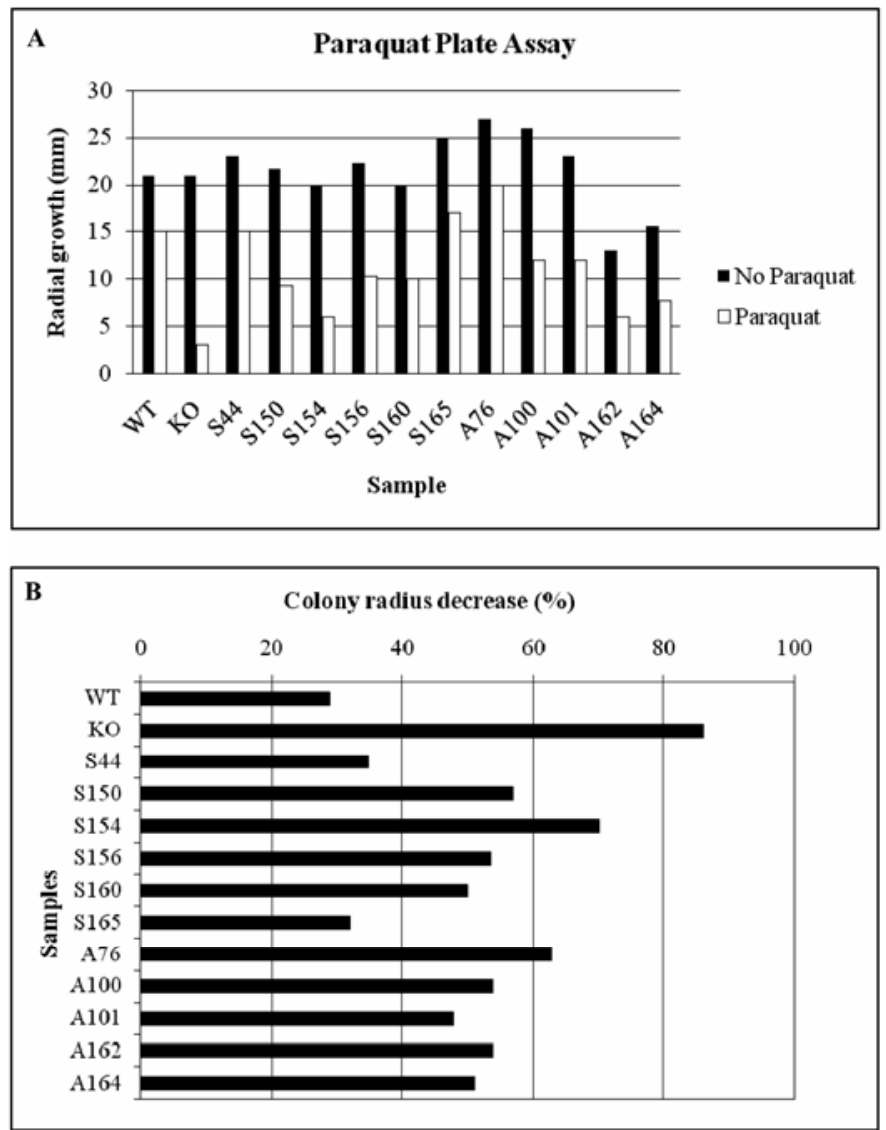

Fig. 3. Paraquat plate assay showing radial mycelial growth of six chosen transformants compared with the wild type (WT) and knockout (KO) strain, $\Delta b c s o d 1-1$ of Botrytis cinerea. A, Average raw data showing radial growth $(\mathrm{mm})$ of the wild type and transformants with and without paraquat; B, Percent decrease in radial growth (sample growth with paraquat treatment compared with growth without treatment) with respect to the data in $\mathbf{A}$.

TABLE 2. Frequency of RNA-mediated silencing of bcsodl in Botrytis cinerea

\begin{tabular}{lccccc}
\hline & & \multicolumn{3}{c}{ Silencing levels (no.) } & Transformants with silencing (\%) \\
\cline { 3 - 5 } Transformant & Total (no.) & Not detectable & Intermediate & High & 36 \\
Sense + antisense & 96 & 61 & 19 & 7 & 27 \\
Sense & 51 & 37 & 7 & 9 & 47 \\
Antisense & 45 & 24 & 12 & 9 & 47 \\
\hline
\end{tabular}




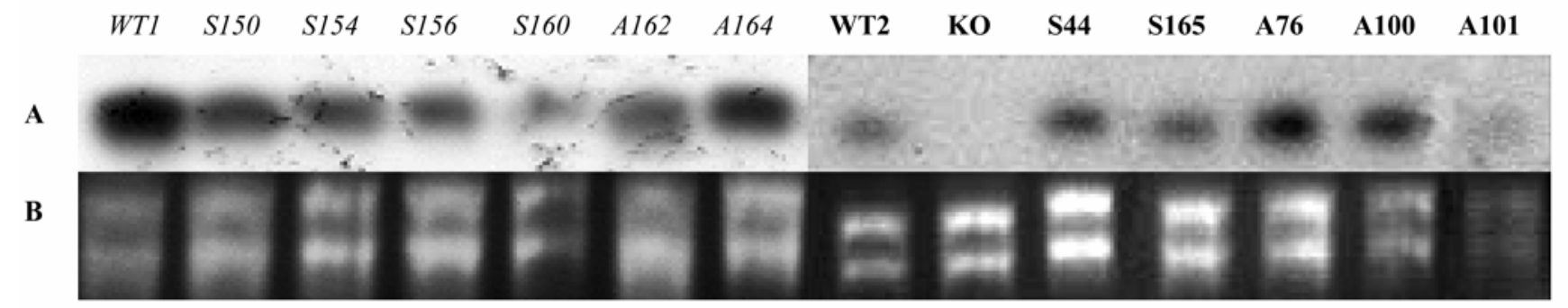

\begin{tabular}{|c|c|c|c|c|c|c|c|c|c|c|c|c|c|}
\hline 100 & 32.2 & 29.0 & 24.0 & 20.8 & 23.0 & 33.8 & 100 & 0 & 96.4 & 76.6 & $>100$ & $>100$ & 74.4 \\
\hline-- & M & $\mathrm{H}$ & $\mathrm{H}$ & $\mathrm{H}$ & $\mathrm{H}$ & M & -- & -- & NS & $\mathrm{L}$ & NS & NS & $\mathrm{L}$ \\
\hline
\end{tabular}

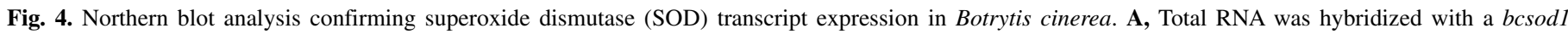

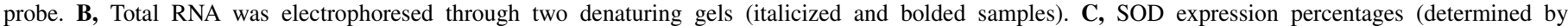

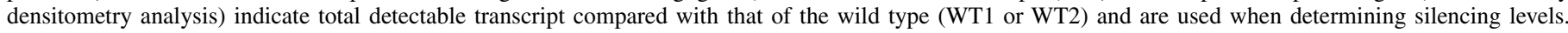

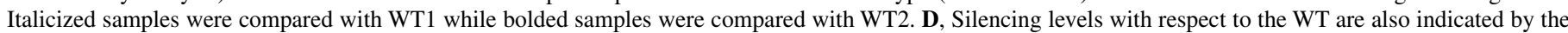

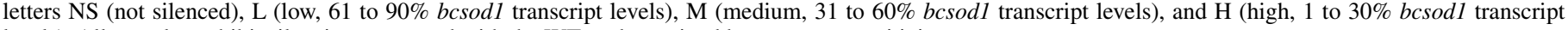
levels). All samples exhibit silencing compared with the WT as determined by paraquat sensitivity.
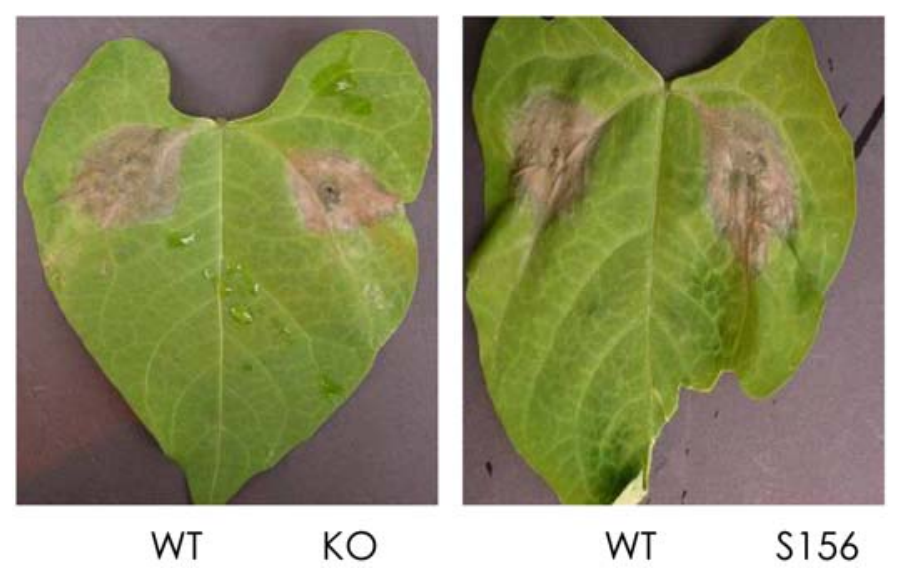

Fig. 5. Example of in planta pathogenicity assay for determining virulence of bcsod1-silenced transformants of Botrytis cinerea compared with the wild type (WT). Sample S156 demonstrates a lesion size equivalent to the wild type (BO5.10). The bcsod1 knockout mutant (KO; $\Delta$ bcsod1-2) displays similar levels in pathogenicity. Punctured plant leaves were inoculated with a single droplet containing conidia from the wild type and transformant (or knockout). Leaves were incubated over a period of 3 days before being photographed. Areas of infection were determined with ImageJ software.

Effects of SOD silencing were also assessed in planta. Previous investigations have found that $\Delta b c$ sodl knockout mutants demonstrated a reduction of virulence on French bean leaves (25). As a result, silenced transformants were hypothesized to vary in virulence levels, which would help to determine residual SOD levels required for normal (wild-type) virulence. Nonetheless, all tested $\Delta b c s o d l$ knockout mutants and the silenced transformants were able to invade plant tissue and cause lesions of sizes similar to the wild type under laboratory conditions. The $\Delta b c s o d l$ knockout mutant did result in highly variable lesion sizes as described by Rolke et al. (25). Even so, statistical analysis indicates that the wild type and knockout mutant do not differ in virulence capabilities. The variations in observed virulence may be caused by differences in French bean cultivar as well as growth conditions (light duration, fertilizers, and so on). For example, in a previous study, broad bean leaflets exhibited an increase in $B$. cinerea resistance when treated with yellow and red lighting (14). Other studies have shown that plant cultivar and growth condition may increase or decrease fungal virulence. For instance, Matheron and colleagues found that powdery mildew infection was dependent upon lettuce cultivar and growth conditions (22). Nutrient availability (nitrogen, sulfur, potassium, and so on) is also able to effect fungal virulence. As a result, variations in fertilizer may directly affect plant resistance capabilities (34). The variations between plate-based analysis and in planta studies of select transformants may result from the high concentrations of free radicals found in the plate-based analyses compared with those of ensuing host-pathogen interactions or the complexities of the AOS pathway. High concentrations of free radicals found in the plate-based assays may not be overcome by the fungus, resulting in a diminished growth rate, while the host tissue defensive response may not employ a high oxidative stress response, allowing unhampered fungal growth rates. Recent studies have quantified free radical concentration on infected host tissue (20) but pose ambiguous results; it is unknown what proportion of free radicals is produced by the host versus the pathogen or the ratio of stable to unstable free radicals. The detoxification of intracellular $\mathrm{H}_{2} \mathrm{O}_{2}$ (generated by the fungus) by $B$. cinerea is also essential to fungal detoxification during infection. Enzymes involved in the detoxification process are unclear and need to be characterized $(5,31)$. Hence, further investigation of total free radical production and neutralization during Botrytis spp. infection is needed before conclusions can be made. Therefore, our investigations have shown that, although silencing is possible in B. cinerea, initial plate-based screening may not be sufficient for identifying potential pathogenic factors. Instead, a combination of in vitro and in planta analyses should be used to determine true fungal virulence.

\section{ACKNOWLEDGMENTS}

We thank M. Heneghan (University of Bristol) for providing the pMCS004 expression vector, P. Tudzynski (University of Munster, Germany) for providing the SOD cDNA and knockout mutants, and M. Pearson (University of Auckland, New Zealand) for his input and ongoing collaborations. This research has been made possible by the generosity of the LESARS (University of Bristol, UK) funding body.

\section{LITERATURE CITED}

1. Altschul, S. F., Gish, W., Miller, W., Myers, E. W., and Lipman, D. J. 1990. Basic local alignment search tool. J. Mol. Biol. 215:403-410.

2. Baulcombe, D. C. 1996. RNA as a target and an initiator of posttranscriptional gene silencing in transgenic plants. Plant Mol. Biol. 32:7988 .

3. Bernstein, E., Denli, A. M., and Hannon, G. J. 2001. The rest is silence. RNA 7:1509-1521.

4. Buttner, P., Koch, F., Voigt, K., Quidde, T., Risch, S., Blaich, R., Bruckner, B., and Tudzynski, P. 1994. Variations in ploidy among isolates of Botrytis cinerea: Implications for genetic and molecular analyses. Curr. Genet. 25:445-450. 
5. Cogoni, C., Irelan, J. T., Schumacher, M., Schmidhauser, T. J., Selker, E. U., and Macino, G. 1996. Transgene silencing of the al-1 gene in vegetative cells of Neurospora is mediated by a cytoplasmic effector and does not depend on DNA-DNA interactions or DNA methylation. EMBO J. 15:3153-3163.

6. Elad, Y., Yunis, H., and Katan, T. 1992. Multiple fungicide resistance to benzimidazoles, dicarboximides and diethofencarb in field isolates of Botrytis cinerea in Israel. Plant Pathol. 41:41-46.

7. Fitzgerald, A., van Kan, J. A. L., and Plummer, K. M. 2004. Simultaneous silencing of multiple genes in the apple scab fungus, Venturia inaequalis, by expression of RNA with chimeric inverted repeats. Fungal Genet. Biol. 41:963-971.

8. Fridovich, I. 1998. Oxygen toxicity: A radical explanation. J. Exp. Biol. 201:1203-1209.

9. Fulci, V., and Macino, G. 2007. Quelling: Post-transcriptional gene silencing guided by small RNAs in Neurospora crassa. Curr. Opin. Microbiol. 10:199-203.

10. Hamada, W., Reignault, P., Bompeix, G., and Boccara, M. 1994. Transformation of Botrytis cinerea with the hygromycin B resistance gene, hph. Curr. Genet. 26:251-255.

11. Hamilton, A. J., and Baulcombe, D. C. 1999. A species of small antisense RNA in posttranscriptional gene silencing in plants. Science 286:950-952.

12. Hammond, S. M., Boettcher, S., Caudy, A. A., Kobayashi, R., and Hannon, G. J. 2001. Argonaute2, a link between genetic and biochemical analyses of RNAi. Science 293:1146-1150.

13. Hannon, G. J. 2002. RNA interference. Nature 418:244-251.

14. Islam, S. Z., Honda, Y., and Arase, S. 1998. Light-induced resistance of broad bean against Botrytis cinerea. J. Phytopathol. 146:479-485.

15. Jarvis, W. R. 1977. Botryotinia and Botrytis species; taxonomy, physiology and pathogenicity. In: Monograph No. 15. Canadian Department of Agriculture, Ottawa, ONT, Canada.

16. Kadotani, N., Nakayashiki, H., Tosa, Y., and Mayama, S. 2003. RNA silencing in the phytopathogenic fungus Magnaporthe oryzae. Mol. PlantMicrobe Interact. 16:769-776.

17. Katan, T. 1982. Persistence of dicarboximide-fungicide resistance in populations of Botrytis cinerea in a warm, dry temperate agroclimate. Phytoparasitica 10:209-211.

18. Kooter, J. M., Matzke, M. A., and Meyer, P. 1999. Listening to the silent genes: Transgene silencing, gene regulation and pathogen control. Trends Plant Sci. 4:340-347.

19. Leroux, P., and Clerjeau, M. 1985. Resistance of Botrytis cinerea Pers and Plasmopara viticola (Berk and Curt) Berl and Detoni to fungicides in French Vineyards. Crop. Prot. 4:137-160.

20. Lyon, G. D., Goodman, B. A., and Williamson, B. 2004. Botrytis cinerea perturbs redoc processes as an attack strategy in plants. In: Botrytis: Biology, Pathology and Control Kluwer Academic Publishers, London.

21. MacRae, I. J., Zhou, K. H., Li, F., Repic, A., Brooks, A. N., Cande, W. Z., Adams, P. D., and Doudna, J. A. 2006. Structural basis for doublestranded RNA processing by dicer. Science 311:195-198.

22. Matheron, M. E., McCreight, J. D., Tickes, B. R., and Porchas, M. 2005. Effect of planting date, cultivar, and stage of plant development on incidence of Fusarium wilt of lettuce in desert production fields. Plant Dis. 89:565-570.

23. Nakayashiki, H., Hanada, S., Nguyen, B. Q., Kadotani, N., Tosa, Y., and
Mayama, S. 2005. RNA silencing as a tool for exploring gene function in ascomycete fungi. Fungal Genet. Biol. 42:275-283.

24. Napoli, C., Lemieux, C., and Jorgensen, R. 1990. Introduction of a chimeric chalcone synthase gene into Petunia results in reversible cosuppression of homologous genes in trans. Plant Cell 2:279-289.

25. Rolke, Y., Liu, S., Quidde, T., Williamson, B., Schouten, A., Weltring, K.M., Siewers, V., Tenberge, K. B., Tudzynski, B., and Tudzynski, P. 2004. Functional analysis of $\mathrm{H}_{2} \mathrm{O}_{2}$ generating systems in Botrytis cinerea: The major $\mathrm{Cu}-\mathrm{Zn}$-superoxide dismutase $(B C S O D 1)$ contributes to virulence on French bean, whereas a glucose oxidase $(B C G O D 1)$ is dispensable. Mol. Plant Pathol. 5:17-27.

26. Romano, N., and Macino, G. 1992. Quelling: Transient inactivation of gene expression in Neurospora crassa by transformation with homologous sequences. Mol. Microbiol. 6:3343-3353.

27. Saiki, R. K., Gelfand, D. H., Stoffel, S., Scharf, S. J., Higuchi, R., Horn, G. T., Mullis, K. B., and Erlich, H. A. 1988. Primer-directed enzymatic amplification of DNA with a thermostable DNA polymerase. Science 239:487-491.

28. Sambrook, J., Fritsch, E. J., and Maniatis, T. 1989. Molecular Cloning. A Laboratory Manual. Cold Spring Harbor Laboratory Press., Cold Spring Harbor, NY.

29. Schouten, A., Tenberge, K. B., Vermeer, J., Stewart, J., Wagemakers, L., Williamson, B., and van Kan, J. A. L. 2002. Functional analysis of an extracellular catalase of Botrytis cinerea. Mol. Plant Pathol. 3:227-238.

30. Schouten, A., Wagemakers, L., Stefanato, F. L., van der Kaaij, R. M., and van Kan, J. A. L. 2002. Resveratrol acts as a natural profungicide and induces self-intoxication by a specific laccase. Mol. Microbiol. 43:883-894.

31. Smith, N. A., Singh, S. P., Wang, M. B., Stoutjesdijk, P. A., Green, A. G., and Waterhouse, P. M. 2000. Total silencing by intron-spliced hairpin RNAs. Nature 407:319-320.

32. van der Vlugt-Bergmans, C. J., Wagemakers, C. A., and van Kan, J. A. L. 1997. Cloning and expression of the catalase A gene of Botrytis cinerea. Mol. Plant-Microbe Interact. 10:21-29.

33. van Kan, J. A. L., van't Klooster, J. W., Wagemakers, C. A., Dees, D. C., and van der Vlugt-Bergmans, C. J. 1997. Cutinase A of Botrytis cinerea is expressed, but not essential, during penetration of gerbera and tomato. Mol. Plant-Microbe Interact. 10:30-38.

34. Walters, D. R., and Bingham, I. J. 2007. Influence of nutrition on disease development caused by fungal pathogens: Implications for plant disease control. Ann. Appl. Biol. 151:307-324.

35. Waterhouse, P. M., Wang, M. B., and Lough, T. 2001. Gene silencing as an adaptive defence against viruses. Nature 411:834-842.

36. Wesley, S. V., Helliwell, C. A., Smith, N. A., Wang, M. B., Rouse, D. T., Liu, Q., Gooding, P. S., Singh, S. P., Abbott, D., Stoutjesdijk, P. A., Robinson, S. P., Gleave, A. P., Green, A. G., and Waterhouse, P. M. 2001. Construct design for efficient, effective and high-throughput gene silencing in plants. Plant J. 27:581-590.

37. Williamson, B., Tudzynski, B., Tudzynski, P., and van Kan, J. A. L. 2007. Botrytis cinerea: The cause of grey mould disease. Mol Plant Pathol. 8:561-580

38. Yuan, Y. R., Pei, Y., Chen, H. Y., Tuschl, T., and Patel, D. J. 2006. A potential protein-RNA recognition event along the RISC loading pathway from the structure of $A$. aeolicus Argonaute with externally bound siRNA. Structure 14:1557-1565 